\title{
Alzheimer Disease and Mood
}

Yee Jung Kim and Steven Karceski, MD

Neurology ${ }^{\circledR}$ 2021;97:e1363-e1366. doi:10.1212/WNL.0000000000012607

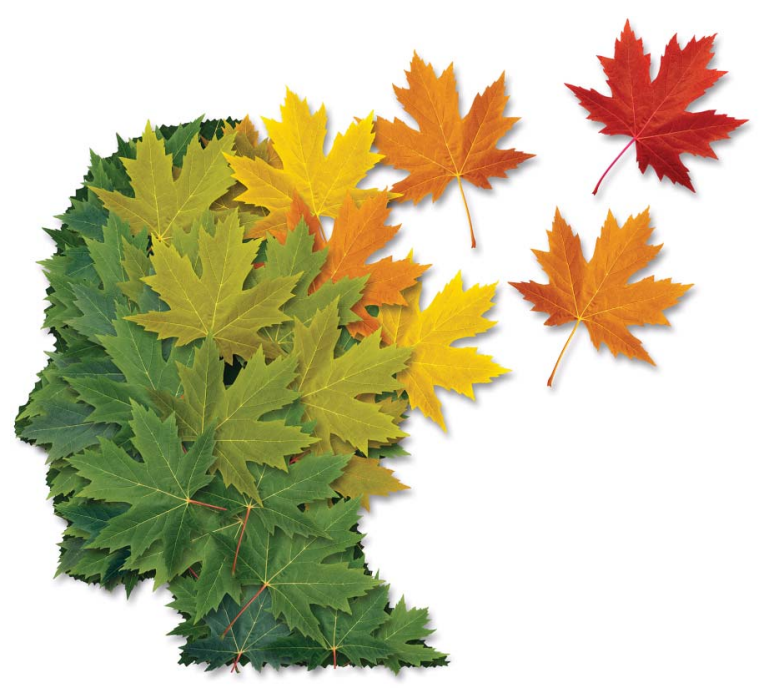

Related Article

Neuropsychiatric and Cognitive Symptoms Across the Alzheimer Disease Clinical Spectrum: Crosssectional and Longitudinal Associations

http://dx.doi.org/10.1212/ WNL.0000000000012598

Alzheimer disease (AD) is a widely known type of dementia. It is an irreversible brain disease that slowly affects memory, thinking, and behavior. In the brain, brain cells talk to each other with special signals, helping people control their minds and bodies. People with AD have lower amounts of these signals. One possible reason for this is that people with AD also have a buildup of a specific protein called amyloid- $\beta$ that prevents their brain cells from communicating with each other. When this happens, a person begins to act and think differently. They may start to show strange behavior or experience delusions. The person may also start showing mood symptoms like aggression, depression, or anxiety. Together, mood symptoms are also called neuropsychiatric symptoms (NPS). In addition, people with AD gradually lose cognitive function. Loss of cognitive abilities are separate from NPS. They include things like troubles with reasoning, memory, problem solving, or mathematical or verbal skills.

\section{How Was the Study Done?}

Willem Eikelboom headed up a group of researchers from Amsterdam, the Netherlands. They wanted to see whether NPS and cognitive functioning in Alzheimer disease influence each other. They assembled a total of 1,524 people, recruited from patients who had gone to the Alzheimer Center Amsterdam during a specific 15-year period (June 2002 through December 2017). All individuals had confirmed accumulation of the amyloid- $\beta$ protein in their brain; this had been determined through specific testing. However, not all individuals had developed dementia yet. In order to assess the patients' NPS and level of cognitive functioning, the researchers gave the patients specific tests. The test for NPS was called the Neuropsychiatric Inventory (NPI), which has 12 sections. These sections include questions about hallucinations, depression, impulsivity, and sleep and appetite changes. Each section is scored based on its severity (on a scale of 0-3) and frequency (on a scale of 0-4). Cognitive functioning was tested using a neuropsychological assessment, including tests like the Trail-Making Test, Digit Span, and Rey Auditory Verbal Learning Test. These tests covered 5 domains including memory, attention, executive functioning, language, and visuospatial abilities.

\section{What Did the Study Show?}

The results of the tests showed that all people in the study who had AD, no matter how serious, had a high level of NPS. However, there was no clear relationship seen between the NPS and the severity of the level of cognitive functioning and decline over time in people with AD. 


\section{Why Is This Important?}

Although the results of prior studies are mixed, many doctors and researchers had thought NPS worsened at the same time as the cognitive decline in a person with $A D$. This study did not find that association. Instead, Dr. Eikelboom and colleagues found that there was no direct increase in NPS with the progression in severity of AD. Instead, their study showed that NPS occur in all stages of AD, including mild ones. In fact, Dr. Eikelboom and his group observed that the NPS may even precede the development of cognitive decline.

This study provided useful information that could help doctors improve care for patients with $A D$. Before this study was done, it was assumed that while a person with AD had a decline in thinking, NPS would get worse at the same time. However, this study showed that it is difficult to predict the progression of NPS. Rather than having a single, specific treatment plan for all patients with $A D$, the authors suggested that it is important to individualize the treatment of NPS for every person with AD.

\section{Strengths and Limitations of the Study}

One of the strengths of this study was that all of the participants were amyloid- $\beta$ positive. In other words, the authors confirmed the diagnosis of AD in the brain for each person included in the study using a biomarker of the illness. In addition, all participants were tested using comprehensive cognitive testing. In addition to the study's strengths, there were some weaknesses. One is that the participants were relatively young compared to the typical age of people with AD. The mean age of the people in the study was 66.3 years. Because of this, it may not be reasonable to apply the findings to older people with AD. In addition, the authors did not take into consideration that some of these patients are on medications for AD. These medications could affect the results. In other words, medications may have blurred the progression of both NPS and cognitive decline. 


\section{About Alzheimer Disease}

Adapted from: Karceski S. The effects of long-term medication use in Alzheimer disease. Neurology 2021;96:e2247-e2250.

\section{What Is Alzheimer Disease?}

Alzheimer disease (AD) is the most common cause of dementia. Dementia is defined as "a condition that affects memory and thinking." When it is more severe, dementia interferes with a person's daily life. However, it takes a long time for a person with dementia to become impaired. Modern research suggests that dementia takes years to develop. Some estimates suggest that the loss of brain function happens over the course of 1-2 decades. A person with dementia starts out with typical thinking abilities, and very gradually develops problems with memory. Misplacing keys, forgetting appointments, and mixing up details (like in a recipe) are common. It is easy to see how a person with mild dementia could overlook these concerns and attribute them to just getting older.

When a person has dementia, the trouble with thinking and memory is very subtle at first. At this stage, it is called mild cognitive impairment. Later, as the dementia worsens, the person has a harder time performing complex tasks. Cooking, and the planning that is required to complete such a task, becomes harder. Tasks like keeping track of bills, appointments, and friends' names get more difficult as well. When the condition is more severe, a person's judgment is affected. Emotions can change, most often coming out as depression. A person's language can become impaired as well, and they can have increasing trouble finding the right word to say. At some point, the thought processes are so severely affected that the person can no longer complete usual daily activities.

It is at the point when the problem significantly affects the person's daily life that the term dementia is used, rather than mild cognitive impairment. There are many different causes of dementia. Of these, $A D$ is the most common. Because of this, people often use the terms dementia and $A D$ interchangeably. About 5.5 million Americans have AD. It is estimated that more than 360,000 new cases occur each year. This number will probably increase as the population ages, because aging itself is a major risk factor for the development of AD. AD is the sixth leading cause of death for adults. It kills more than 100,000 Americans each year.

\section{What Are the Symptoms?}

Loss of recent memories (also called short-term memory) is one of the earliest signs of dementia. For instance, people with dementia may repeat stories in the same conversation. They may forget the details of the previous day, such as where they went. They may not recall the details of a movie they recently watched. Other signs include frequently misplacing belongings or having difficulty doing familiar tasks, even things they may have done many times before. They might have trouble finding the right words to say and may not follow the details of long conversations. For some people, there can also be changes in mood, behavior, or personality.

Because dementia and $A D$ are so gradual, in the early stages, many people fail to recognize that something is wrong. They may assume that such behavior is a normal part of getting older, or that they are "just having a senior moment." Although forgetting things is common, if it is something that is getting worse, it may be a sign of a more serious problem. The key to treatment of $A D$ is early diagnosis. It is critical to see a doctor when one recognizes or suspects AD symptoms.

\section{How Is AD Diagnosed?}

When $A D$ is suspected, it is important to have a complete medical and neurologic workup. In the first doctor's visit, a detailed history and examination are needed. Often, blood tests are ordered, and brain imaging studies are requested (such as an MRI). Additional testing, such as a PET scan, can help in making the diagnosis. Neuropsychological testing is often performed. This is done both to help make the diagnosis and to follow how the person's brain function changes over time. For some people, a lumbar puncture (also known as a spinal tap) may be needed. This may be done to rule out illnesses that can mimic AD.

\section{What Causes AD?}

The cause of $A D$ is not fully known. It is not contagious. Although genetic forms of $A D$ have been identified, the most common form does not run in families.

\section{What Are the Treatments?}

Although there is no cure for $A D$, there are treatments that may help with the symptoms of AD. The cognitive symptoms of $A D$ should be treated as early as possible to slow the progression of the disease. Drugs called cholinesterase inhibitors may be considered in people with mild to moderate disease. Vitamin E may also slow progression, but it should only be used if prescribed by a doctor.

\section{Behavioral Problems}

Behaviors such as suspicion, paranoia, aggression, or resistance to care may be treated first by understanding what triggers these behaviors. Caregivers may learn how to change things in the person's environment to avoid or minimize these triggers. Some examples include providing low lighting and music to improve eating, taking regular walks, scheduling toileting, and following consistent routines. Sometimes, medications 
are needed to help with mood problems such as depression.

\section{Prevention}

Ongoing research suggests that there are many ways to keep your brain healthy. Avoiding harmful substances such as alcohol and drugs and exercising the body regularly have been shown to preserve brain function. It is also important to exercise the mind. Social interactions, reading, and playing games are just a few ways that we can constantly challenge our brains, keeping them healthy for as long as possible.

\section{For More Information}

Brain \& Life

brainandlife.org

Alzheimer's Association alz.org/

Alzheimer's Foundation of America alzfdn.org/ 


\title{
Neurology
}

\author{
Alzheimer Disease and Mood \\ Yee Jung Kim and Steven Karceski \\ Neurology 2021;97;e1363-e1366 \\ DOI 10.1212/WNL.0000000000012607
}

This information is current as of September 27, 2021

\section{Updated Information \&} Services

Permissions \& Licensing

\section{Reprints}

including high resolution figures, can be found at: http://n.neurology.org/content/97/13/e1363.full

Information about reproducing this article in parts (figures,tables) or in its entirety can be found online at:

http://www.neurology.org/about/about_the_journal\#permissions

Information about ordering reprints can be found online:

http://n.neurology.org/subscribers/advertise

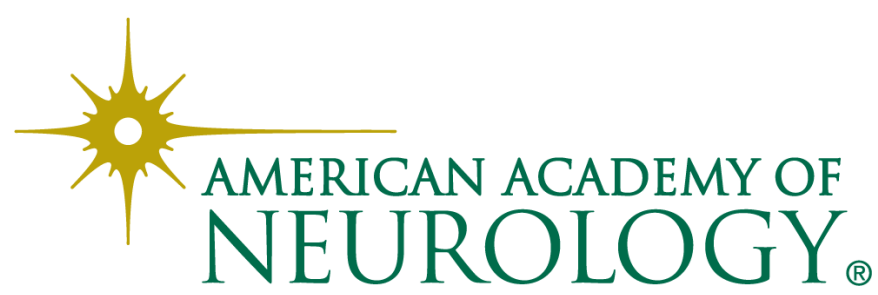

